\title{
Rapid visuomotor preparation in the human brain: a functional MRI study
}

Citation for published version (APA):

Adam, J. J. M. E., Backes, W. H., Rijcken, J. M., Hofman, P. A. M., Kuipers, H., \& Jolles, J. (2003). Rapid visuomotor preparation in the human brain: a functional MRI study. Cognitive Brain Research, 16(1), 1-10. https://doi.org/10.1016/S0926-6410(02)00204-5

Document status and date:

Published: 01/01/2003

DOI:

10.1016/S0926-6410(02)00204-5

Document Version:

Publisher's PDF, also known as Version of record

\section{Please check the document version of this publication:}

- A submitted manuscript is the version of the article upon submission and before peer-review. There can be important differences between the submitted version and the official published version of record.

People interested in the research are advised to contact the author for the final version of the publication, or visit the DOI to the publisher's website.

- The final author version and the galley proof are versions of the publication after peer review.

- The final published version features the final layout of the paper including the volume, issue and page numbers.

Link to publication

\footnotetext{
General rights rights.

- You may freely distribute the URL identifying the publication in the public portal. please follow below link for the End User Agreement:

www.umlib.nl/taverne-license

Take down policy

If you believe that this document breaches copyright please contact us at:

repository@maastrichtuniversity.nl

providing details and we will investigate your claim.
}

Copyright and moral rights for the publications made accessible in the public portal are retained by the authors and/or other copyright owners and it is a condition of accessing publications that users recognise and abide by the legal requirements associated with these

- Users may download and print one copy of any publication from the public portal for the purpose of private study or research.

- You may not further distribute the material or use it for any profit-making activity or commercial gain

If the publication is distributed under the terms of Article $25 \mathrm{fa}$ of the Dutch Copyright Act, indicated by the "Taverne" license above, 


\title{
Rapid visuomotor preparation in the human brain: a functional MRI study
}

\author{
Jos J. Adam ${ }^{\mathrm{a}, *}$, W. Backes ${ }^{\mathrm{b}}$, J. Rijcken ${ }^{\mathrm{a}}$, P. Hofman ${ }^{\mathrm{b}}$, H. Kuipers ${ }^{\mathrm{a}}$, J. Jolles ${ }^{\mathrm{c}}$ \\ ${ }^{a}$ Department of Movement Sciences, Maastricht University, Maastricht, The Netherlands \\ ${ }^{\mathrm{b}}$ Department of Radiology, Academic Hospital Maastricht, Maastricht, The Netherlands \\ ${ }^{\mathrm{c}}$ Department of Neuropsychology and Psychiatry, Maastricht University, Maastricht, The Netherlands
}

Accepted 11 July 2002

\begin{abstract}
An important feature of human motor behaviour is anticipation and preparation. We report a functional magnetic resonance imaging study of the neuronal activation patterns in the human brain that are associated with the rapid visuomotor preparation of discrete finger responses. Our imaging results reveal a large-scale distributed network of neural areas involved in fast visuomotor preparation, including specific areas in the frontal cortex (middle frontal gyrus, premotor and supplementary motor cortex), the parietal cortex (intra-parietal sulcus, inferior and superior parietal lobe) and the basal ganglia. Our reaction time results demonstrate that it is easier to prepare two fingers on one hand than on two hands. This hand-advantage phenomenon was associated with relatively enhanced levels of activity in the basal ganglia and relatively reduced levels of activity in the parietal cortex. These findings provide direct evidence for differential activity in a distributed brain system associated with specific neuro-computational operations subserving fast visuomotor preparation.

(c) 2002 Elsevier Science B.V. All rights reserved.
\end{abstract}

Theme: Motor systems and sensorimotor integration

Topic: Cortex

Keywords: Basal ganglia; Frontal cortex; Parietal cortex; Supplementary motor area

\section{Introduction}

Functional neuroimaging techniques such as functional magnetic resonance imaging (fMRI) and positron emission tomography (PET) —in combination with paradigms drawn from cognitive psychology-have proven to be extremely useful for investigating brain mechanisms underlying different aspects of human movement, including motor execution [40], motor learning [27], and motor imagery [13]. In contrast, the neural correlates of motor preparation in humans have received little attention. This is unfortunate as motor preparation precedes motor execution, with faulty or incomplete preparation often resulting in faulty or suboptimal execution [21]. Moreover, the nervous system

\footnotetext{
*Corresponding author. Faculty of Health Sciences, Maastricht University, P.O. Box 616, 6200 MD Maastricht, The Netherlands. Tel.: +31-43-388-1389; fax: +31-43-367-0972.

E-mail address: jos.adam@bw.unimaas.nl (J.J. Adam).
}

appears to be anticipatory rather than reactive, stressing the relevance of anticipation and thus preparation [21,34].

According to Deiber et al. [12], the paucity of neuroimaging data on motor preparation in humans is due-at least in part - to the limited temporal resolution of PET and fMRI. This technical constraint hampers the delineation of the preparatory and execution phases of movement. As noted by Deiber et al. [12], using extremely long preparation intervals of up to $90 \mathrm{~s}$ [28] does not help much, because processes other than motor preparation might intrude, including visuospatial working memory or mental imagery.

To circumvent these problems, Deiber et al. [12] used a relatively short preparation interval (averaging about $4 \mathrm{~s}$ ) in combination with a reaction time paradigm that minimised (but did not eliminate) the involvement of execution-related processes relative to the preparation-related processes. They adopted the movement precuing paradigm developed by Rosenbaum [36] to control and manipulate 
the processes of motor preparation. In this technique, a precue or preparatory signal precedes the presentation of the reaction signal by a certain time interval. The function of the precue is to provide advance information about the movement to be executed, thereby allowing selective motor preparation. The information contained in the precue often varies, allowing complete, partial, or no advance preparation of the forthcoming movement.

Deiber et al. [12] used a preparatory stimulus that provided either full, partial, or no information regarding two variables of a forthcoming right finger movement: finger type (index or little finger) and movement direction (abduction or elevation). As expected, their results showed that reaction time (RT) was longest in the 'no' information condition, intermediate in the 'partial' information condition, and shortest in the 'full' information condition (approximately 800, 500, and $300 \mathrm{~ms}$, respectively). In other words, RT decreased with an increasing amount of advance information, strongly indicating that participants did make use of the precue information and selectively prepared responses.

In comparison with a 'rest' condition where no response was required, all these three information conditions showed increased activation values in a common set of cerebral regions: the frontal cortex (sensorimotor, premotor, cingulate, and supplementary cortex), the parietal association cortex (anterior and posterior regions), the cerebellum, the basal ganglia, and the thalamus. Thus, using PET, Deiber et al. inferred the participation of these cerebral structures in the (general) preparation for movement. However, because motor execution processes also were involved in the three preparation conditions, it is possible that they too contributed to the observed effects; hence, some caution in accepting Deiber et al.'s [12] conclusion seems warranted.

The goal of the present investigation was to extend the study by Deiber et al. [12] on human motor preparation by using a different neuroimaging method-namely fMRIand a new motor task that allowed a clean separation of preparatory and execution processes. Note that this is not the first study to focus on fMRI in the investigation of motor preparation; earlier reports are studies by Lee et al. [30] and Cui et al. [11]. We used a specific variant of Rosenbaum's movement precuing paradigm [36], namely the finger-precuing task devised by Miller [31].This task requires subjects to respond to spatial-location stimuli with discrete responses from index and middle fingers of both hands that are placed adjacently. The display consists of three horizontal rows, representing warning, precue, and target stimulus, respectively. The warning stimulus consists of four plus $(+)$ signs, indicating the four possible stimulus locations. The precue consists of two plus signs, indicating two possible stimulus locations. The target stimulus consists of one plus sign, indicating the target stimulus location. The temporal order of these three rows is as follows: first the warning stimulus is presented, then, after a delay that is typically constant, the precue, and then, after a delay that is typically variable, the target stimulus. The variable delay is called the preparation interval, as it reflects the amount of time subjects are given to selectively prepare the two finger responses indicated by the precue, before the imperative target stimulus is presented. In other words, the functional significance of the precue is that it transforms the original four-choice reaction task into a two-choice reaction task.

Four precue conditions are distinguished. In the handcued condition, the precue specifies two fingers on the same hand (e.g., the left-middle and left-index fingers). In the finger-cued condition, the precue specifies the same finger on different hands (e.g., the left-index and rightindex fingers). In the neither-cued condition, the precue specifies different fingers on different hands (e.g., the left-middle and right-index fingers). Also, an uncued condition is included. Here, the 'precue' provides no advance information (it contains plus signs in all four possible stimulus locations), and thus precludes selective preparation of any combination of two finger responses. This condition is a control condition because it leaves the basic, four-choice reaction task unaltered. Because the Hick-Hyman law [22,24] states that a two-choice reaction task results in shorter RTs than a four-choice reaction task, precue effectiveness is inferred from a significant RT benefit for the two-choice precue conditions (i.e., handcued, finger-cued, and neither-cued) relative to the control, four-choice uncued condition. In Fig. 1, the finger precuing task is presented schematically.

A robust finding from the finger precuing task is a pattern of differential precuing benefits [33]. RTs are shortest for the hand-cued condition and longest for the neither-cued condition, with the finger-cued condition being intermediate. This pattern of differential precuing benefits is apparent primarily at short preparation intervals (intervals less than $1,500 \mathrm{~ms}$ ). When the preparation interval is extended to $3 \mathrm{~s}$, all three precue conditions show similar RTs. Thus, certain pairs of responses can be selected and prepared more quickly than others, with no differences between the pairs once the responses have been selected and prepared.

Our choice for the finger-precuing task to study the neural mechanisms of visuomotor preparation was motivated by several considerations. First, the finger-precuing task uses spatially compatible precues, and not spatially incompatible or symbolic precues as in the Deiber et al. [12] study; this reduces the complexity of cue decoding processes and allows a more direct perception-action coupling. Second, the spatially compatible precues in the finger-precuing paradigm allow the use of extremely short preparation intervals to effectuate a selective preparatory motor set [3,31]; this further reduces-perhaps even eliminates - the possible involvement of working memory or mental imagery processes. Third, and most importantly, all four preparation conditions (including the uncued 


\section{Finger Precuing Task}

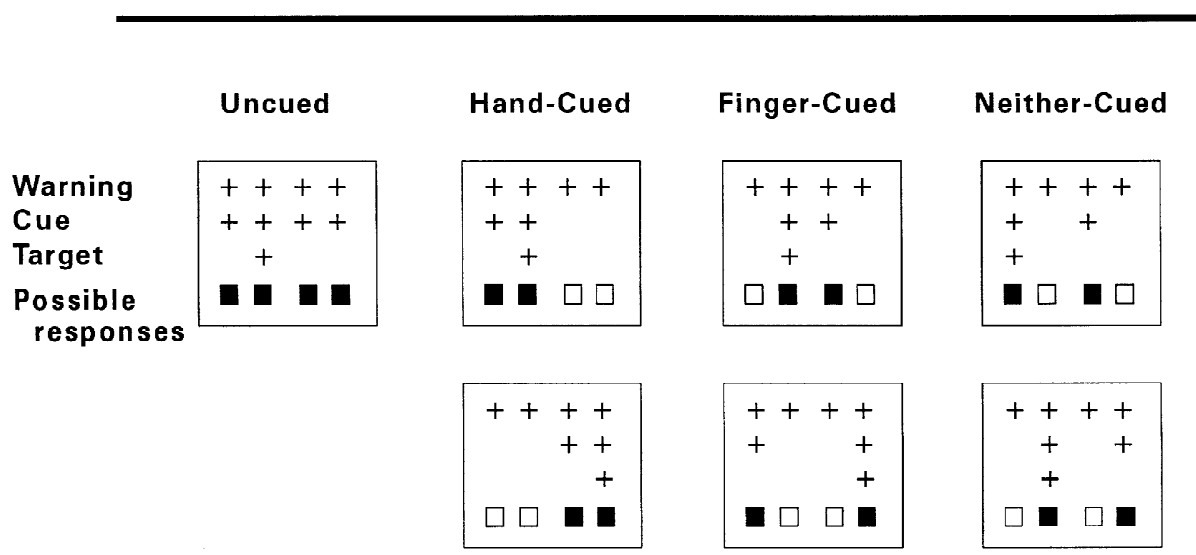

Fig. 1. Schematic representation of the finger precuing task and the four preparation conditions. The black squares indicate the possible responses indicated by the cue, and thus reflect the number and type of prepared responses. Note that in all conditions only one response was actually required, namely the finger response indicated by the single target stimulus.

condition) are identical in terms of motor execution processes (i.e., the same finger responses are involved in all four conditions); they differ only in the opportunity for and type of selective visuomotor preparation. Thus, by comparing and contrasting RTs and brain activation values in the three cued conditions (i.e., hand-cued, finger-cued, and neither-cued) with that in the uncued condition, it is possible to derive a clean (i.e., an 'execution-free') measure of selective visuomotor preparation. This procedure eliminates the problem of distinguishing preparatory from executive phases. Fourth and last, the finger precuing task exhibits a pattern of differential precuing benefits; this raises the theoretically interesting question which neural mechanisms mediate this pattern.

\section{Materials and methods}

\subsection{Subjects}

Fourteen healthy young adults (seven females, mean age 24.5 years; range 20-35 years) gave informed consent in accordance with the Declaration of Helsinki to participate. All subjects were right-handed as determined by simple enquiry. The subjects were screened to rule out a history of neurological or psychiatric conditions, and all had normal or corrected-to-normal vision.

\subsection{Stimuli and apparatus}

Subjects lay at full length on their back in a fMRI scanning apparatus. Stimuli were controlled by a personal computer and were projected with a LCD video projector onto a translucent screen placed above the knees of the subject. The subject was able to see the screen by the use of a mirror system. Responses were made by pressing one of four keys of two response pads (Lumitouch Reply System, Lightwave Medical Industries, Vancouver, Canada). The two response pads were placed along side the body at the level of the upperlegs, so that the subjects could comfortably operate the individual response keys with the index and middle fingers of both hands with their arms stretched. Viewing distance was held constant at about $90 \mathrm{~cm}$. The computer was used to control the timing of the stimulus displays, to synchronize the trigger output signal (TTL, $5 \mathrm{~V}, 5 \mathrm{~ms}$ ) to the MRI system, and to record response latencies and accuracies.

Stimuli were plus signs $(+)$ subtending visual angles of about $0.63^{\circ}$ wide and $0.95^{\circ}$ high. The stimulus display subsequently consisted of a warning signal, a cue signal, and a target signal, with the entire display centred on the viewing screen. The warning signal was a row of four plus signs. One blank space separated the two left-most, and also the two right-most, positions; the two centre positions were separated by two blank spaces After a delay of 750 $\mathrm{ms}$, the cue signal appeared immediately below the warning signal. After a delay of $500 \mathrm{~ms}$ (the preparation interval), the target signal (a single plus sign) appeared immediately below the cue row, always in one of the positions indicated by the cue. The subject's task was to respond as quickly as possible to the position in which the target signal occurred by pressing the appropriate response key. Target signal and response key were mapped onto each other in a spatially compatible manner, such that a target appearing in the left-most position was to be responded to with the left middle finger pressing the left-most response key, etc. An intertrial interval of $1 \mathrm{~s}$ separated the response in a trial from the start of the next trial. 


\subsection{Procedure}

We distinguished four precue or preparation conditions. In the hand-cued condition, the precue specified two fingers on the same hand (e.g., the left-middle and leftindex fingers). In the finger-cued condition, the precue specified the same finger on different hands (e.g., the left-index and right-index fingers). In the neither-cued condition, the precue specified different fingers on different hands (e.g., the left-middle and right-index fingers). These three preparation conditions are called the 'cued' conditions. Also, an uncued condition was included. Here, the 'precue' provides no advance information (it contains plus signs in all four possible stimulus locations), and thus precludes selective preparation of any combination of two finger responses. This condition is a control condition.

There were three scanning sessions, each lasting 8.5 min. In each session, the four preparation conditions were administered twice, in random order, in epochs of $30 \mathrm{~s}$ and alternated by epochs of $30 \mathrm{~s}$ 'resting state'. In the 'resting state' subjects were asked to fixate with their eyes a central fixation cross (an uppercase $\mathrm{X}$ ); this was the baseline condition. Moreover, each session started and ended with a rest epoch, making a total of 17 epochs. Subjects received 16 trials in each experimental epoch (four for each of the four stimulus positions), totalling 96 trials in each of the four preparation conditions.

On the day before testing, subjects performed 160 practice trials (40 for each cue condition) to familiarise themselves with the task. They were informed regarding the nature of the task and were explicitly told to take advantage of the cue. They were instructed to react as quickly as possible to the target stimulus by pressing the correct response key. Error feedback was provided on individual trials.

\section{4. fMRI data acquisition}

Images were acquired on a 1.5 Tesla MR scanner (Philips ACS-NT, Philips Medical Systems), which was equipped with a standard receiver head coil. Head fixation was achieved by two foam cushions and by a tape across the subject's head. The scanner room was dimly lit. On the basis of $\mathrm{T}_{1}$-weighted survey scans in three orthogonal directions, an approximately $13 \mathrm{~cm}$ thick stack of slices was defined, encompassing transversal slices that covered the entire cerebrum and as much as possible of the cerebellum.

The functional scan session consisted of a single shot multiple slice $\mathrm{T}_{2}^{*}$ sensitive echo planar imaging (EPI) sequence, with parameters TR $5000 \mathrm{~ms}$, TE $50 \mathrm{~ms}$, flip angle $90^{\circ}$, matrix dimension $64 \times 64,38$ contiguous slices and an isotropic voxel size of $3.5 \mathrm{~mm}$. The fMRI signal is based on the blood oxygen level dependent (BOLD) effect $[5,6]$. In every subject three runs each containing 103 volumes were acquired. Before the acquisition of func- tional images started, two dummy full brain scans were acquired to run the system in a steady state to avoid switch-on effects. The total acquisition time was almost 9 min for each paradigm. The entire fMRI experiment lasted at most $60 \mathrm{~min}$ per subject, including all acquisitions, reconstructions, instructions to the subject, and checks on the experimental set-up.

For anatomical reference, a three-dimensional (3D) $\mathrm{T}_{1}$ weighted fast-field echo scan succeeded the functional scans with parameters TR $11 \mathrm{~ms}$, TE $3.5 \mathrm{~ms}$, flip angle $90^{\circ}$, matrix dimensions $256 \times 256,150$ transverse contiguous slices and an isotropic voxel size of $1 \mathrm{~mm}$.

\subsection{Data analysis}

The image data were analysed using the Statistical Parametric Mapping (SPM99b, Wellcome Department of Cognitive Neurology, London, UK) software package. The scanned volumes of each subject were first corrected for small motion artefacts by 3D rigid-body realignment. Subsequently, the images were normalised [15] by transformation into standard space, using the EPI template image of the MNI (Montreal Neurological Institute) as a reference to the stereotaxic atlas of Talairach and Tournoux [38]. The voxel sizes of the normalised images were $2 \mathrm{~mm}$ isotropically. The stereotaxic coordinates were used to report the location of the observed activation foci. To enhance the spatial signal to noise ratio and to facilitate inter subject averaging, the normalised images were smoothed with a Gaussian filter with a full-width at half maximum of $8 \mathrm{~mm}$.

For the group analysis, in the SPM design matrix [16] the global activity was considered as a confound which was accounted for by global scaling. Temporal smoothing, a low-pass filter $(1 / 120 \mathrm{~Hz})$ and delaying of the modelled response function by $6 \mathrm{~s}$ were applied to enhance that part of the haemodynamic response that correlated with stimulus sequence [18]. The resulting set of images represent statistical parametric maps of the $t$ statistic $\operatorname{SPM}\{t\}$. The statistical inferences about the deflecting fMRI signal were based on the theory of random Gaussian fields [17] and were corrected for multiple comparisons. The $t$-maps were transformed to the unit normal probability distribution to allow inferences based on Gaussian $P$-values and $Z$-values. For each subject and each condition contrast vectors representing the amplitudes of the activation signal were calculated from the fMRI timeseries using a random effects model [19].

On the resulting group level $t$-maps spherical regions of interest were positioned at the centre of areas showing significant activation $(P \leq 0.05)$. The diameters of the spherical regions of interest were determined from the typical size of the activated area. The spatially averaged activation amplitudes were used for further statistical analysis to compare the precuing conditions.

RTs below $150 \mathrm{~ms}$ or in excess of $1250 \mathrm{~ms}$ were 
considered outliers and were excluded from data analyses; $0.02 \%$ of the trials were removed using this criterion. Mean correct RTs and proportions of errors were calculated for each subject as a function of preparation condition. A one-factor, repeated-measures analysis of variance (ANOVA) was performed on the mean RTs with preparation condition as within-subject variable. Whenever appropriate the tests were adjusted for heterogeneity of variance and covariances using the Huynh-Feldt corrected significance values. Post-hoc analyses were carried out using Tukey's honestly significant (HSD) procedure.

\section{Results}

\subsection{Task performance}

\subsubsection{Reaction time}

The ANOVA revealed a highly significant effect for the factor preparation condition, $F(3,39)=35.09, P<0.001$. The post-hoc analysis indicated faster RTs for all three cued conditions relative to the uncued condition (see Fig. 2 ). This finding indicates that subjects engaged in selective visuomotor preparation in the hand-, finger-, and neithercued conditions. Furthermore, the three cued conditions differed among themselves (all $P$ values $<0.05$ ), with the hand-cued condition producing the shortest RTs and thus showing the largest preparation effect. This outcome is consistent with previous reports [33].

\subsubsection{Errors}

Mean error rate was $2.3 \%$. This figure was deemed too low to permit a meaningful statistical analysis. Subjects made most errors in the uncued and neither cued conditions (mean $=3.0$ and $3.3 \%$, respectively), fewest in the hand-cued condition (mean $=0.9 \%$ ), and an intermediate number of errors in the finger-cued condition (mean= $1.9 \%$ ). Thus, generally, the conditions that showed the longest RTs also produced the most errors.

\subsection{Activation areas}

\subsubsection{Comparison of task performance with baseline}

Table 1 indicates the coordinates of the areas of significant activation $(P<0.01)$ associated with the visuomotor task (i.e., averaged over the four preparation conditions) in comparison with the baseline condition. Because the preparation interval was short (i.e., $500 \mathrm{~ms}$ ), subjects spent about as much time in motor preparation as in motor execution. Therefore, it is impossible to relate the observed neuronal activity listed in Table 1 to preparatory rather than to executive processes, or vice versa. To get an 'execution-free' measure of selective motor preparation it is imperative to compare activation levels between preparation conditions, in particular activation levels in the three

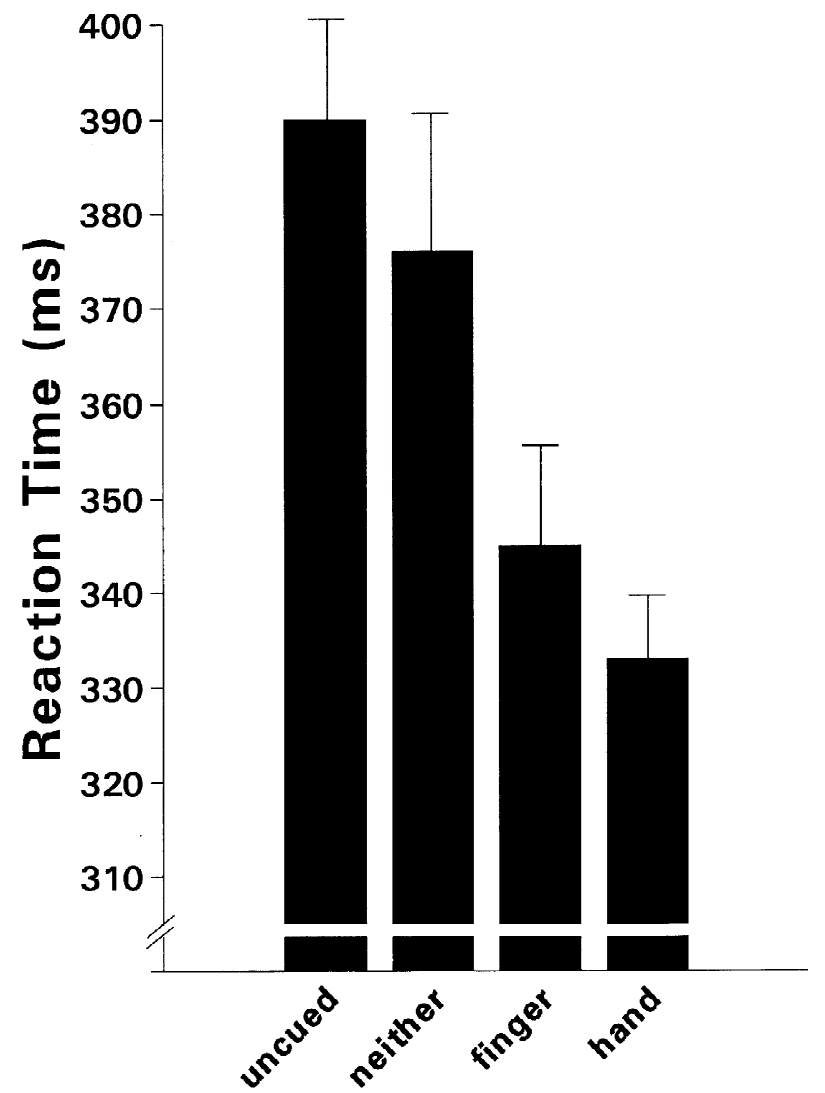

\section{Preparation Condition}

Fig. 2. Task performance in terms of mean reaction time (ms) averaged over the 14 subjects in each of the four preparation condition (mean+ S.E.M.).

cued conditions (i.e., hand-, finger-, and neither-cued) with that in the uncued condition.

\subsubsection{Comparisons between preparation conditions}

To assess the effect of preparation condition on the intensity of activation we conducted a two-factor, repeated-measures, ANOVA for each of the structures listed in Table 1. The two factors in these analyses were preparation condition (uncued, hand-cued, finger-cued, and neither-cued) and hemisphere of activation (left and right). For all, but two brain areas, the factor hemisphere did not produce significant $F$-values. Therefore, in this section, we focus on the results of the factor preparation condition, and the data, thus, represent values averaged over the left and right hemisphere. Table 2 lists the brain areas that yielded a significant $F$-value for the factor preparation condition, indicating significant differences in activation as a function of preparation condition.

Generally, the post-hoc analyses revealed distinct areas with increased activation values in the hand-, finger-, and neither-cued conditions relative to the uncued condition. That is, in comparison with the uncued condition, the three 
Table 1

Sites of activation during the finger precuing task compared with the baseline condition (stereotaxic coordinates are expressed in millimeters)

\begin{tabular}{|c|c|c|c|c|c|c|}
\hline \multirow[t]{2}{*}{ Brain region } & \multirow[t]{2}{*}{ BA } & \multirow{2}{*}{$\begin{array}{l}\text { ROI } \\
(r-m m)\end{array}$} & \multicolumn{3}{|c|}{ Coordinates } & \multirow[t]{2}{*}{$Z$-score } \\
\hline & & & $x$ & $y$ & $z$ & \\
\hline \multicolumn{7}{|l|}{ Frontal cortex } \\
\hline medial frontal cortex/cingulate & $6 / 24 / 32$ & 6 & 0 & 4 & 54 & 3.4 \\
\hline middle frontal cortex (L) & $8 / 9$ & 2 & -44 & 40 & 34 & 2.3 \\
\hline middle frontal cortex $(\mathrm{R})$ & & & 54 & 26 & 28 & 1.8 \\
\hline lateral premotor cortex $(\mathrm{L})$ & 6 & 6 & -52 & 6 & 34 & 3.1 \\
\hline lateral premotor cortex (R) & & & 52 & 8 & 36 & 3.4 \\
\hline dorsal premotor cortex (L) & 6 & 4 & -28 & -6 & 58 & 3.4 \\
\hline dorsal premotor cortex (R) & & & 36 & -4 & 62 & 3.3 \\
\hline inferior frontal cortex (L) & 44 & 4 & -48 & 8 & -4 & 2.8 \\
\hline inferior frontal cortex (R) & & & 52 & 16 & -8 & 3.0 \\
\hline supplementary motor area (L) & 6 & 2 & -18 & -8 & 68 & 3.4 \\
\hline supplementary motor area (R) & & & 12 & -2 & 68 & 3.1 \\
\hline Sensori-motor cortex (L) & $1-4$ & 4 & -34 & -14 & 62 & 3.0 \\
\hline Sensori-motor cortex (R) & & & 38 & -18 & 62 & 3.1 \\
\hline \multicolumn{7}{|l|}{ Parietal cortex } \\
\hline inferior parietal cortex (L) & 40 & 6 & -40 & -38 & 50 & 3.5 \\
\hline inferior parietal cortex (R) & & & 50 & -36 & 50 & 3.8 \\
\hline intra-parietal sulcus (L) & $40 / 7$ & 6 & -36 & -54 & 52 & 3.6 \\
\hline intra-parietal sulcus ( $\mathrm{R})$ & & & 36 & -56 & 48 & 3.8 \\
\hline superior parietal cortex (L) & 7 & 6 & -20 & -70 & 48 & 3.6 \\
\hline superior parietal cortex (R) & & & 26 & -70 & 46 & 3.8 \\
\hline \multicolumn{7}{|l|}{ Occipitotemporal cortex } \\
\hline lateral occipital/inferior temporal (L) & $19 / 37$ & 6 & -46 & -74 & 0 & 3.3 \\
\hline lateral occipital/inferior temporal (R) & & & 50 & -68 & -2 & 3.7 \\
\hline primary visual cortex (L) & $17 / 18$ & 4 & -10 & -94 & -10 & 4.0 \\
\hline primary visual cortex (R) & & & 14 & -92 & -4 & 3.8 \\
\hline \multicolumn{7}{|l|}{ Subcortical } \\
\hline lateral cerebellum (L) & & 6 & -34 & -58 & -32 & 3.5 \\
\hline lateral cerebellum (R) & & & 38 & -56 & -32 & 3.7 \\
\hline medial cerebellum $(\mathrm{L})$ & & 4 & -12 & -74 & -46 & 3.6 \\
\hline medial cerebellum $(\mathrm{R})$ & & & 10 & -72 & -44 & 3.4 \\
\hline caudate nucleus (L) & & 4 & -12 & 0 & 10 & 2.1 \\
\hline caudate nucleus (R) & & & 8 & 2 & 6 & 2.1 \\
\hline putamen (L) & & 4 & -24 & 2 & 4 & 2.5 \\
\hline putamen (R) & & & 24 & 2 & 4 & 2.6 \\
\hline thalamus (L) & & 4 & -14 & -12 & 12 & 2.9 \\
\hline thalamus ( R) & & & 12 & -14 & 14 & 2.8 \\
\hline superior colliculus (L) & & 2 & -6 & -24 & -10 & 2.1 \\
\hline superior colliculus (R) & & & 10 & -26 & -10 & 2.5 \\
\hline
\end{tabular}

BA Brodmann area. ROI = region of interest. $\mathrm{L}=$ left; $\mathrm{R}=$ right. Coordinates are according to the atlas of Talairach and Toumoux [38].

cued conditions showed increased activation levels in a common set of cerebral regions with most consistent foci in the frontal cortex (middle frontal gyrus, premotor and supplementary motor cortex), the parietal cortex (inferior and superior parietal lobe, intra-parietal sulcus), and the basal ganglia (caudate nucleus and putamen). This outcome indicates that these structures are involved in rapid, selective visuomotor preparation (see Fig. 3).

In addition, there were also significant differences in activation values between the hand-, finger-, and neithercued conditions. This is illustrated in Fig. 4, which depicts the general amount of activation as a function of prepara- 
Table 2

Activation values of brain areas showing more activation in the hand-, finger-, and neither-cued conditions than in the uncued condition (values are averaged over left and right hemispheres)

\begin{tabular}{|c|c|c|c|c|c|c|}
\hline \multirow[t]{2}{*}{ Brain region } & \multicolumn{4}{|c|}{ Preparation condition } & \multirow[t]{2}{*}{$F(3,39)$} & \multirow[t]{2}{*}{$P$} \\
\hline & uncued & hand & finger & neither & & \\
\hline \multicolumn{7}{|l|}{ Frontal cortex } \\
\hline middle frontal cortex & 1.8 & 10.4 & 8.7 & 7.9 & 5.39 & 0.01 \\
\hline lateral premotor cortex & 11.9 & 16.8 & 14.5 & 16.7 & 2.87 & 0.05 \\
\hline dorsal premotor cortex & 14.6 & 19.0 & 16.2 & 19.1 & 4.44 & 0.01 \\
\hline supplementary motor area & 9.1 & 12.8 & 11.5 & 11.6 & 3.70 & 0.05 \\
\hline \multicolumn{7}{|l|}{ Parietal cortex } \\
\hline inferior parietal cortex & 18.8 & 20.2 & 21.4 & 24.8 & 3.14 & 0.05 \\
\hline intra-parietal sulcus & 18.2 & 20.8 & 22.2 & 25.1 & 7.62 & 0.001 \\
\hline superior parietal cortex & 26.9 & 28.9 & 30.6 & 33.8 & 2.97 & 0.05 \\
\hline \multicolumn{7}{|l|}{ Basal ganglia } \\
\hline caudate nucleus & 1.0 & 6.4 & 1.6 & 3.9 & 3.99 & 0.05 \\
\hline putamen & 1.2 & 6.8 & 4.1 & 5.2 & 5.17 & 0.01 \\
\hline
\end{tabular}

For the Brodmann areas and stereobaxic coordinates of the brain areas see Table 1.

tion condition in the prefrontal lobe, parietal lobe, and basal ganglia (that is, averaged over the relevant sub-areas within these general brain regions). In the frontal cortex, there were no significant differences between the hand-, finger-, and neither-cued conditions $(P>0.3)$. In the basal ganglia, the hand-cued condition showed the highest level of activation $(P<0.05)$, whereas in the parietal cortex the

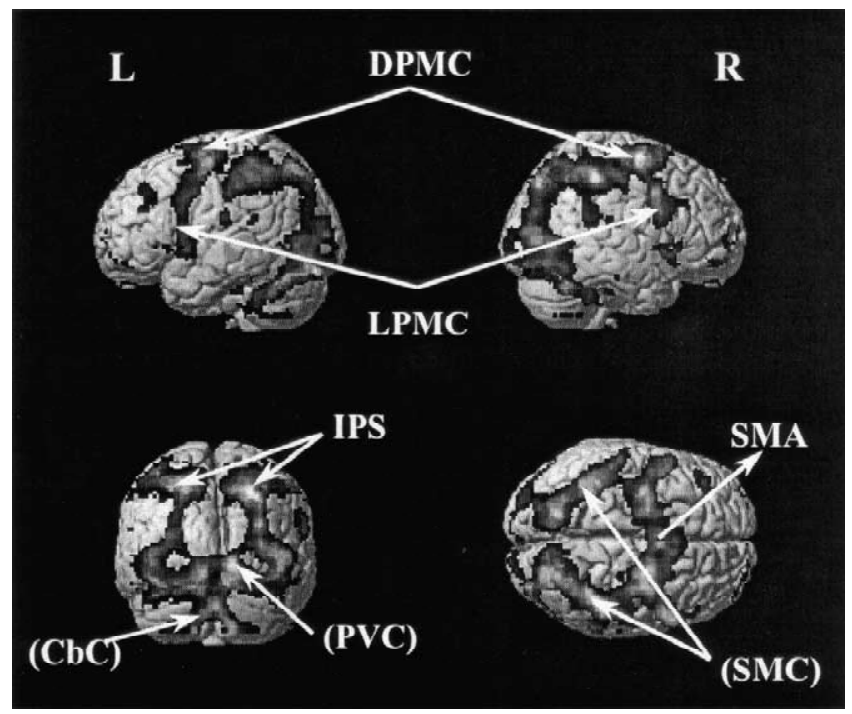

Fig. 3. Activation $(t)$ maps of the group analysis indicating the cortical structures involved in rapid, visuomotor preparation in the hand-cued condition. The structures listed in parentheses (i.e., the primary visual cortex, the sensorimotor cortex, and the cerebellum) are not part of this network but are shown to illustrate the areas involved in visual processing and motor execution). $\mathrm{CbC}=$ Cerebellar cortex; $\mathrm{DPMC}=$ dorsal premotor cortex; IPS = intra-parietal cortex; LPMC = lateral premotor cortex; $\mathrm{PVC}=$ primary visual cortex; $\mathrm{SMA}=$ supplementary motor area; $\mathrm{SMC}=$ sensorimotor cortex; $\mathrm{L}=$ left; $\mathrm{R}=$ right. neither-cued condition showed the highest level of activation $(P<0.01)$. This pattern of different activation values for the hand-, finger-, and neither-cued conditions as a function of brain area was statistically confirmed by a 3 (preparation condition) $\times 3$ (brain area), repeated measures ANOVA, that revealed a significant interaction between preparation condition and brain area $[F(4,52)=5.53, P<$ 0.001].

\subsubsection{Hemispheric differences}

Two brain areas showed a differential amount of activa-

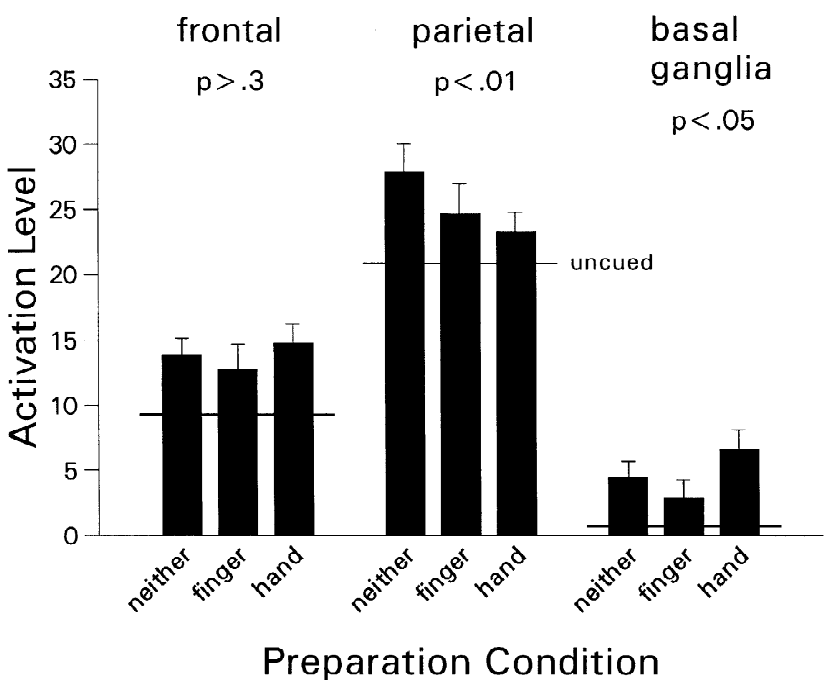

Fig. 4. Activation level (in arbitrary units) in the prefrontal cortex, parietal cortex, and basal ganglia as a function of preparation condition (mean + S.E.M.). The $P$-values are associated with one-way ANOVAs conducted on the factor Preparation Condition for each of these brain areas. 
tion in the two hemispheres, with the left hemisphere showing greater activity than the right hemisphere. This was found for the intra-parietal sulcus [means $=24.8 \mathrm{vs}$. 18.4 , respectively; $F(1,13)=4.68, P<0.05]$ and for the primary visual cortex $[$ means $=33.5$ vs. 22.4 , respectively; $F(1,13)=11.41, P<0.001]$.

\section{Discussion}

This study used fMRI methods and short duration cues (i.e., $500 \mathrm{~ms}$ ) to investigate the neural mechanisms of rapid visuomotor preparation. The RT results showed a RT advantage for the hand-, finger-, and neither-cued conditions relative to the uncued condition. This finding demonstrates the involvement of selective visuomotor preparation in these conditions. The fMRI data showed that this visuomotor preparation was associated with increased activation levels in a common set of cerebral regions: the frontal cortex (middle frontal gyrus, premotor and supplementary motor cortex), the parietal cortex (inferior and superior parietal lobule, intra-parietal sulcus), and the basal ganglia (caudate nucleus and putamen). This outcome indicates that these structures are part of a network for rapid visuomotor preparation.

\subsection{A single anatomic substrate for rapid visuomotor preparation}

The RT results indicated significant differences between the hand-, finger-, and neither-cued conditions, suggesting the operation of distinct preparatory processes. Interestingly however, these differences in RT were not paralleled by the involvement of distinct neural brain mechanisms as the same brain areas were activated in each of the three preparation conditions. This finding suggests a single anatomic substrate for rapid visuomotor preparation, a conclusion consistent with prior work of Deiber et al. who also reported the operation of a common set of cerebral regions for different conditions of motor preparation. In the study by Deiber et al., this network included the sensorimotor cortex, the premotor, cingulate, and supplementary motor cortex, the parietal cortex, as well as the basal ganglia, thalamus, and cerebellum. The additional involvement of the sensorimotor cortex, cingulate, thalamus, and cerebellum in the Deiber et al. study might be related to (a) the longer preparation interval (4 s) allowing more complete and/or intense preparation; and/ or (b) motor execution processes, whose contribution, even though minimised by the experimental procedure, can not be disregarded completely. That is, neuroimaging studies have provided evidence for a role of the primary sensorimotor cortex [7], the anterior cingulate cortex [32], and the cerebellum [20] in motor execution function.

Even though we did not find Deiber et al.'s result of significant thalamic involvement in motor preparation, it should be noted that there was a trend in our data for greater thalamic activity in all three cued conditions relative to the uncued condition; however, this effect was only marginally significant $(P<0.1)$.

In summary, the present study replicated and extended the Deiber et al. study. In particular, it replicated Deiber et al.'s finding of a single anatomic substrate for human motor preparation; it extended Deiber et al.'s study by using a more clean measure of motor preparation (allowing a more pure determination of its neural substrates), and by demonstrating that this single anatomic substrate for motor preparation also holds when motor preparation is extremely fast (that is, following very short-500 ms-duration precues) and based on spatial instead of symbolic precues.

\subsection{Neural mechanisms of the hand-advantage}

Our RT results showed that it is easier to prepare two fingers on one hand than on two hands. Apparently, neuronal processing is most efficient when responses can be selected and prepared within one hemisphere. This hand-advantage phenomenon was associated with increased activity in the basal ganglia and decreased activity in the parietal cortex. Therefore, the observed hand-advantage has two components.

\subsubsection{Parietal cortex}

First, the visual spatial precue is processed in the cortex of the parietal lobe which is thought to derive multiple representations of space, tailored to guide specific types of action, such as eye, head, and arm movements [8,9]. Thus, parietal areas-together with the frontal areas to which they are connected-mediate distinct sensorimotor transformations related to motor control [35].

Importantly, models of spatial processing have emphasized the grouping and segmentation operations that create structural units or objects according to Gestalt principles $[4,14]$. These grouped parts tend to gain or lose processing capacity together. According to evidence provided by Adam [2], the visual cue indicating preparation of fingers on one single hand represents a natural, strong (left or right) perceptual subgroup that is established quickly and automatically. In contrast, the less natural and more complex finger- and neither-cues that are positioned on both sides of the visual hemispace require more complex processing to create a subgroup, thereby producing higher fMRI activity. Therefore, according to this view, the handadvantage reflects - at least in part - the stronger spatial grouping of the two leftmost and two rightmost cueelements requiring minimal information processing. Moreover, according to this view, the appearance of a left/right cue might evoke a reflexive attentional orienting response, which may 'prime' or activate automatically the appropriate response [10]. The present finding that the handadvantage was associated with reduced levels of activity in 
the parietal cortex is in concordance with this interpretation of the hand-advantage.

An alternative interpretation of the hand advantage is the 'spatial proximity' hypothesis. According to this hypothesis preparation for two stimulus positions is more efficient the closer together they are, possibly because of an advantage in sharing attention across nearby positions [31]. This hypothesis, however, can be rejected because the observed effects do not support the explanation. That is, the spatial proximity hypothesis would predict shorter RTs when the index fingers are precued than when the middle fingers are precued, simply because the precue locations are in closer proximity in the former situation than in the latter. Our results, however, contradict this prediction: RTs were virtually identical for preparing two middle or two index fingers (means $=342$ and $343 \mathrm{~ms}$, respectively; for similar findings see Refs. [1,31,33]).

\subsubsection{Basal ganglia}

Second, selecting motor responses may implicate inhibiting the non-desirable ones [26]. Physiologically, the output from the basal ganglia is inhibitory. The strong subcortical activity in the basal ganglia associated with the hand-cued condition might be interpreted in terms of a robust inhibition process generated by the basal ganglia and targeted at one hemisphere (that is, the hemisphere representing the two irrelevant responses). Supposedly, general inhibition of the (pre)motor cortex of one hemisphere is easier to implement than the more specific inhibition of two irrelevant responses represented in two hemispheres. Note that in the latter case, relevant and irrelevant responses are represented by neighbouring or bordering neural areas, necessitating a finer spatial discrimination process than when the relevant and irrelevant responses are located in separate hemispheres. Future experimentation using an event-related design that allows separation of left and right hand responses might prove useful in testing this conjecture [39].

The recent demonstration that the basal ganglia are involved in changing response parameters, but not in the recognition of stimulus patterns [23], accords with our suggestion that the hand advantage has two loci: a perceptual locus originating in the parietal cortex, and a motoric locus originating in the basal ganglia.

\subsection{Hemispheric differences}

The intra-parietal sulcus and the primary visual cortex showed greater activity in the left than in the right hemisphere. The finding of enhanced activity in the left intra-parietal sulcus is consistent with evidence showing a left parietal dominance for motor intention or preparation [37]. The enhanced activity in the left primary visual cortex is more difficult to interpret, but perhaps it may be accounted for by the notion that the left hemisphere is biased to and more adept at processing high spatial frequency (or local) information, whereas the right hemisphere is better at processing low-frequency (or global) information [25,29]. According to this view, the enhanced activity in the left visual cortex is related to the small visual angles occupied by the target stimulus, necessitating the processing of high spatial frequency information.

\section{Conclusion}

The present fMRI neuroimaging study isolated a distributed network of neural areas involved in fast visuomotor preparation. This network included portions of the frontal cortex, the parietal cortex, and the basal ganglia. The present evidence indicates that this system modulated activity in the parietal cortex and basal ganglia as a function of preparation condition. When the cue indicated the selective preparation of two fingers on one hand, activity in the basal ganglia increased; when the cue indicated selective preparation of two different fingers on two hands, activity in the parietal cortex increased. These findings provide direct evidence for differential activity in a distributed brain system associated with specific neurocomputational operations subserving visuomotor preparation. A challenge for the future would be to investigate this neural network in patients showing a motor preparation deficit (e.g., Parkinson's disease).

\section{References}

[1] J.J. Adam, The spatial proximity hypothesis of the hand advantage in spatial precuing tasks, Hum. Movement Sci. 11 (1992) 641-652.

[2] J.J. Adam, Manipulating the spatial arrangement of stimuli in a precuing task, Acta Psychol. 85 (1994) 183-202.

[3] J.J. Adam, F.G.W.C. Paas, J.C. Teeken, E.M. van Loon, M.P.J. van Boxtel, P.J. Houx, J. Jolles, Effects of age on performance in a finger precuing task, J. Exp. Psychol.: Hum. Percept. Perform. 24 (1998) 870-883.

[4] Y. Adini, D. Sagi, Parallel processes within the 'spot-light' of attention, Spatial Vision 6 (1992) 61-77.

[5] P.A. Bandettini, E.C. Wong, R.S. Hinks, R.S. Tikofsky, J.S. Hyde, Time-course EPI of human brain function during task activation, Magnetic Reson. Med. 25 (1992) 390-398.

[6] J.W. Belliveau, D. Kennedy, R.C. McKinstry, B.R. Buchbinder, R.M. Weisskoff, M.S. Cohen, J.M. Vevea, T.J. Brady, B.R. Rosen, Functional mapping of the human visual cortex by magnetic resonance imaging, Science 254 (1991) 716-719.

[7] R. Chen, C. Gerloff, M. Hallett, L.G. Cohen, Involvement of the ipsilateral motor cortex in finger movements of different complexities, Ann. Neurol. 41 (1997) 247-254.

[8] C.L. Colby, J.-R. Duhamel, Spatial representations for action in parietal cortex, Cogn. Brain Res. 5 (1996) 105-115.

[9] C.L. Colby, M.E. Goldberg, Space and attention in parietal cortex, Annu. Rev. Neurosci. 22 (1999) 319-349.

[10] L. Craighero, L. Fadiga, C.A. Umiltà, G. Rizzolatti, Evidence for visuomotor priming effect, Neuroreport 8 (1996) 347-349.

[11] S.-Z. Cui, E.-Z. Li, Y.-F. Zang, X.-C. Weng, R. Ivry, J.-J. Wang, Both sides of human cerebellum involved in preparation and 
execution of sequential movements, Neuroreport 11 (2000) 38493853.

[12] M.-P. Deiber, V. Ibañez, N. Sadato, M. Hallett, Cerebral structures participating in motor preparation in humans: a positron emission tomography study, J. Neurophysiol. 75 (1996) 233-247.

[13] J. Decety, D. Perani, M. Jeannerod, V. Bettinardi, B. Tadary, R. Woods, J.C. Mazziotta, F. Fazio, Mapping motor representations with PET, Nature 371 (1994) 600-602.

[14] J. Duncan, Cooperating brain systems in selective perception and action, in: T. Inui, J.L. McClelland (Eds.), Attention and Performance XVI. Information Integration in Perception and Communication, MIT Press, Cambridge, 1996, pp. 549-578.

[15] K.J. Friston, J. Ashburner, C.D. Frith, J.-B. Poline, J.D. Heather, R.S.J. Frackowiak, Spatial registration and normalization of images, Hum. Brain Mapp. 2 (1995) 165-189.

[16] K.J. Friston, A.P. Holmes, K.J. Worsley, J.-B. Poline, C.D. Frith, R.S.J. Frackowiak, Statistical parametric maps in functional imaging: a general linear approach, Hum. Brain Mapp. 2 (1995) 189210.

[17] K.J. Friston, A. Holmes, J.-B. Poline, C.J. Price, C.D. Frith, Detecting activations in PET and fMRI: levels of inference and power, Neuroimage 40 (1996) 223-235.

[18] K.J. Friston, P. Jezzard, L. Turner, Analysis of functional MRI time-series, Hum. Brain Mapp. 1 (1994) 153-171.

[19] K.J. Friston, A.P. Holmes, C.J. Price, C. Buchel, K.J. Worsley, Multisubject fMRI studies and conjunction analyses, Neuroimage 10 (1999) 385-396.

[20] S.T. Grafton, J.C. Mazziotta, R.P. Woods, M.E. Phelps, Human functional anatomy of visually guided finger movements, Brain 115 (1992) 565-587.

[21] M. Hallet, Disorder of movement preparation in dystonia, Brain 9 (2000) 1765-1766.

[22] W.E. Hick, On the rate of gain of information, Q. J. Exp. Psychol. 4 (1952) 11-26.

[23] S.A. Huettel, P.B. Mack, G. McCarthy, Perceiving patterns in random series: dynamic processing of sequence in prefrontal cortex, Nat. Neurosci. 5 (2002) 485-490.

[24] R. Hyman, Stimulus information as a determinant of reaction time, J. Exp. Psychol. 45 (1953) 188-196.

[25] R.B. Ivry, L.C. Robertson, The Two Sides of Perception, MIT Press, London, 1998.

[26] M. Jeannerod, The Cognitive Neuroscience of Action, Blackwell, Oxford, 1997

[27] M. Jueptner, K.M. Stephan, C.D. Frith, D.J. Brooks, R.S.J. Frac- kowiak, R.E. Passingham, Anatomy of motor learning. I. Frontal cortex and attention to action, J. Neurophysiol. 77 (1997) 13131324.

[28] R. Kawashima, P.E. Roland, B.T. O'Sullivan, Fields in human motor areas involved in preparation for reaching, actual reaching, and visuomotor learning: a positron emission tomography study, J. Neurosci. 14 (1994) 3462-3474.

[29] F. Kitterle, S. Christman, J. Hellige, Hemispheric differences are found in identification, but not detection of low versus high spatial frequencies, Percept. Psychophys. 48 (1990) 297-306.

[30] K.-M. Lee, K.-H. Chang, J.-K. Roh, Subregions within the supplementary motor area activated at different stages of movement preparation and execution, Neuroimage 9 (1999) 117-123.

[31] J. Miller, Discrete versus continuous models of human information processing: in search of partial output, J. Exp. Psychol.: Hum. Percept. Perform. 8 (1982) 273-296.

[32] T. Paus, M. Petrides, A.C. Evans, E. Meyer, Role of the human anterior cingulate cortex in the control of oculomotor, manual, and speech responses: a positron emission tomography study, J. Neurophysiol. 70 (1993) 453-469.

[33] T.G. Reeve, R.W. Proctor, The salient-features coding principle for spatial- and symbolic-compatibility effects, in: R.W. Proctor, T.G. Reeve (Eds.), Stimulus-Response Compatibility, North-Holland, Amsterdam, 1990, pp. 163-180.

[34] J. Requin, J. Brener, C. Ring, Preparation for action, in: J.R. Jennings, M.G.H. Coles (Eds.), Handbook of Cognitive Psychophysiology: Central and Autonomic Nervous System Approaches, Wiley, New York, 1991, pp. 357-448.

[35] G. Rizzolatti, L. Fogassi, V. Gallese, Parietal cortex: from sight to action, Curr. Opin. Neurobiol. 7 (1997) 562-567.

[36] D.A. Rosenbaum, The movement precuing technique: assumptions, applications, and extensions, in: R.A. Magill (Ed.), Memory and Control of Action, North-Holland, Amsterdam, 1983, pp. 231-274.

[37] M.F. Rushworth, P.D. Nixon, S. Renowde, D.T. Wade, R.E. Passingham, The left parietal cortex and motor attention, Neuropsychologia 35 (1997) 1261-1273.

[38] J. Talairach, P. Tournoux, Co-Planar Stereotaxic Atlas of the Human Brain, George Thieme Verlag, Stuttgart, 1988.

[39] I. Toni, D. Thoenissen, K. Zilles, Movement preparation and motor intention, Neuroimage 14 (2001) S110-117.

[40] C.J. Winstein, S.T. Grafton, P.S. Pohl, Motor task difficulty and brain activity: investigation of goal-directed reciprocal aiming using positron emission tomography, J. Neurophysiol. 77 (1997) 15811594. 